\title{
Thermal Sensations During a Partial-Body Cryostimulation Exposure in Elite Basketball Players
}

\author{
by \\ Romain Bouzigon ${ }^{1,3}$, Gilles Ravier ${ }^{1}$ Benoit Dugue ${ }^{2}$, Frederic Grappe ${ }^{1}$
}

\begin{abstract}
Partial-body cryostimulation is used to improve recovery after exercise, especially during competitions or heavy training; however, a limited number of studies have been conducted with international-level athletes in situ during competitions. This study was undertaken to assess the thermal sensation ratings during 3 min of cold exposure $\left(a t-130^{\circ} \mathrm{C}\right.$ ) in 24 international-level athletes during the European Basketball Championship. The mean thermal sensation score, measured using a perceptive scale, increased significantly $(p<0.05)$ during partial-body cryostimulation exposure in athletes from $3.0 \pm 1.7$ at $30 \mathrm{~s}$ to $5.7 \pm 2.3$ at $3 \mathrm{~min}$ (maximal observed value $=10.0$ ). The mean value of 5.7 is considered a "cold" sensation on the scale (ranging from $0=$ neutral sensation to $10=$ very cold). However, we observed a large inter-individual variation in the perceived thermal sensations. The body mass index was significantly and negatively correlated with the thermal sensation value after $2 \mathrm{~min} 30 \mathrm{~s}$ and 3 min of exposure in females $(r=-0.61, n=13, p<0.05 ; r=-0.56, n=13, p=0.054$, respectively). Three participants reported high perceived thermal sensation after $30 \mathrm{~s}$ of exposure and their cold-induced discomfort worsened as the exposure continued. In conclusion, a 3-min exposure is globally well tolerated by athletes and can be used during a heavy competition period and/or during a training period. However, special attention should be given to female athletes with a low body mass index as they seem to be much more sensitive to cold.
\end{abstract}

Key words: competition, cryotherapy, international-level athletes, perceived cold sensation, recovery.

\section{Introduction}

Partial body cryostimulation (PBC) consists of extreme cold exposure lasting from 1 to $4 \mathrm{~min}$ in a cabin with an air temperature of -130 ${ }^{\circ} \mathrm{C}$ (according to the manufacturer) or less in minimal clothing (a bathing suit, cap, gloves, socks, slippers) (Bouzigon et al., 2016). PBC apparatus is an open cabin where subjects, excluding the head and neck, are exposed. This technique is used to treat pain and inflammation, recover faster after injuries or surgery, improve the quality of life in patients suffering inflammatory pathologies and recover faster after physical exercise (Banfi et al., 2010; Dugue and
Leppanen, 2000; Dugue, 2015; Lombardi et al., 2017; Miller et al., 2016; Mikołajec et al., 2017).

Though not completely clear, the mechanism leading to recovery improvement seems to be related to cold-induced analgesia and a lower level of exercise-induced inflammation (Hausswirth et al., 2011; Leppaluoto et al., 2008; Pournot et al., 2011). Stimulation of the sympathetic system, release of noradrenalin and vasoconstriction during and after cold exposure have a significant impact on pain and muscle soreness (Leppaluoto et al., 2008). Muscle cooling during and after cold exposure may also

\footnotetext{
1 - Université de Franche Comté, Laboratoire C3S (EA 4660), Unité de Promotion, de Formation et de Recherche (UPFR) des Sports, 31 rue de l'Epitaphe, 25000 Besançon, France.

2 - Université de Poitiers, EA 6314, laboratoire « Mobilité, Vieillissement et Exercice (MOVE) », Faculté des sciences du sport, 86000 Poitiers, France.

3 - Société Cryantal Développement, 15 cours du Luzard, 77186 Noisiel, France.
} 
lower enzyme activities, lower the metabolism and limit protein degradation after exerciseinduced ischemia, which can be an important feature for recovery improvement (Bleakley and Hopkins, 2010; Costello et al., 2012). Moreover, athletes using PBC during high-level international tournaments seem to have an enhanced quality of sleep (Bouzigon et al., 2014). PBC has therefore been well accepted by many athletes and professional sport teams (Banfi et al., 2009). PBC is available in a mobile device which enables its use at training and competition sites.

Benefits of PBC for physical recovery improvement have been demonstrated (Bouzigon et al., 2016). However, whether an exposure at $130^{\circ} \mathrm{C}$ or less is well tolerated by athletes during a competition is questionable. Such exposure could be perceived as too painful, stressful and even dangerous and could lower or eliminate the beneficial effects of cryostimulation. During competition, psychological stress increases in athletes (Filaire et al., 2001). Moreover, international-level athletes are subjects with very special kinds of psychological and physiological adaptations, and when experiencing high levels of stress (e.g. during international competition), they may react differently (Harung et al., 2011; Sternberg et al., 1998) than during periods of lower amounts of physical and psychological loads. Such changes may have an influence on the athlete's thermal sensitive capacities (Sternberg et al., 1998). At the current time, there are no data available concerning cold-perceived sensation in international athletes (Hohenauer et al., 2015), and therefore it is important to assess the thermal sensation during cold exposure in internationallevel athletes during the competitive period.

Anthropometric characteristics including relative mass and size of the contact area are known to influence tissue cooling, transfer of heat from the body and perceived thermal sensations in humans subjected to cold stimuli (Dugue and Leppanen, 2000; Glickman-Weiss et al., 1993; Zhang et al., 2001). Moreover, it seems that gender may also have an effect as females show a different level of perceived thermal sensation than males when exposed to cold stimuli (Cuttell et al., 2017; Hammond et al., 2014).

This study was undertaken to assess the thermal sensation ratings during 3 min of cold exposure (at $-130{ }^{\circ} \mathrm{C}$ ) in elite athletes during international competitions. We examined whether a 3-min $\mathrm{PBC}$ exposure at $-130{ }^{\circ} \mathrm{C}$ remained comfortable for competitive athletes; whether male and female athletes perceived the cold stimulus in a similar way and whether athletes with a lower BMI perceived the cold stimulus in a similar way compared to athletes with a higher BMI. The data obtained in this study should therefore be useful in the world of professional sports, and teams could obtain information on whether PBC is suitable for the athletes during competitions.

\section{Methods}

\section{Participants}

Twenty-four international-level basketball players (13 females and 11 males, aged $25.7 \pm 3.5$ years) from the French national team participated in this study. The athletes' characteristics are presented in Table 1 and were obtained from the team organisers. We calculated the BMI, which is the body mass divided by the square of the body height. Thorough investigations of the athletes were not possible in the context of the European Basketball Championship.

All the participants were informed about the experimental procedure along with the purpose of this study and gave written informed consent. The protocol was approved by the local ethics committee and adhered to the latest amendments of the Declaration of Helsinki.

Design and Procedures

This field study was carried out during the two weeks of the 2013 European Basketball Championship preparation tournament. Cold exposure was performed using PBC apparatus (Universal Cryosana; Mecacel, Mouroux, France), and cooling of the cryocabin was performed with nitrogen spraying inside the chamber. Although the cryo spray did not directly touch the athlete's skin, the temperature through the exposure was adjusted with the nitrogen supply. The PBC device was a mobile PBC integrated in a trunk. The exposures were performed next to the hotel of the French Team. The device was equipped with adjustable walls enabling athletes of different heights to have similar exposure. The PBC procedure was a 3 -min exposure at $-130{ }^{\circ} \mathrm{C}$ that occurred in the afternoon after training (between 4 and $9 \mathrm{pm}$ ). Such a protocol is regularly used in the exercise recovery context and has been shown 
to provide benefits in athletes (Klimek et al., 2010; Mila-Kierzenkowska et al., 2013; Sutkowy et al., 2014). In the cryocabin, athletes wore underwear, gloves, socks and slippers.

\section{Measures}

The perception of thermal sensation during exposure within the cryocabin was recorded every $30 \mathrm{~s}$. The participants were asked to rate their perceptual thermal sensation using a ten-point scale (Lundgren et al., 2014), which had been shown to be valid and reliable to assess human thermal perception in an extremely cold environment (Lundgren et al., 2014). The scale was shown to the participants every $30 \mathrm{~s}$, and the following question was asked: "How cold do you feel right now?". The athletes answered verbally from 0 ("neutral") to 10 ("unbearably cold") (Figure 1), and the given score was registered. All the scores were obtained during the exposure. At the third minute, the thermal sensation was evaluated just before the end of the exposure.

It was not possible to perform other assessments on athletes during competition. Statistical analysis

The statistics program used was Sigmaplot 12.0 Software (Systat Inc. San Jose, CA, USA). The results were expressed as mean and standard deviation (SD). Homogeneity of variance was assessed with a F-test Levene's test. The changes in the evolution of the thermal sensation scores during the exposures in male and female athletes were analysed by a two-way analysis of variance (ANOVA) with repeated measures (Gender $x$ Duration). Thus, the evolution of the thermal sensation score during the exposure was analysed. We also investigated whether the changes in the thermal sensation were similar or different in males and females. Thermal sensation data were logarithmically transformed to reduce non-uniformities of their distribution when they were not normally distributed in a Gaussian manner (Hopkins et al., 2009). Post hoc comparison was performed using the Tukey/Kramer test. Correlation analyses between the BMI and thermal sensation were performed using the Spearman test. The level of statistical significance was set at $p<0.05$.

\section{Results}

Thermal sensation seemed to increase every $30 \mathrm{~s}$ during $\mathrm{PBC}$ exposure in both male and female athletes and in all athletes $(p<0.001 ; \mathrm{F}=$ 37.41). The significant differences between each time interval are shown in Table 2.

The evolution of the thermal sensation scores during exposure was similar in males and females $(p<0.001 ; \mathrm{F}=15.13$ and $p<0.001 ; \mathrm{F}=7.2$, respectively, with no significant interaction). The data obtained at each measurement time are shown in Table 2.

In females, the BMI became significantly and negatively correlated with thermal sensation during the last minute (at $150 \mathrm{~s}: r=-0.61, \mathrm{n}=13, p$ $<0.05$; at $180 \mathrm{~s}: r=-0.56, \mathrm{n}=13, p<0.05)$, i.e. female athletes with a lower BMI had more uncomfortable thermal sensations than female athletes with a higher BMI (Figure 2). No significant correlations between the BMI and perceived thermal scores were found in male athletes.

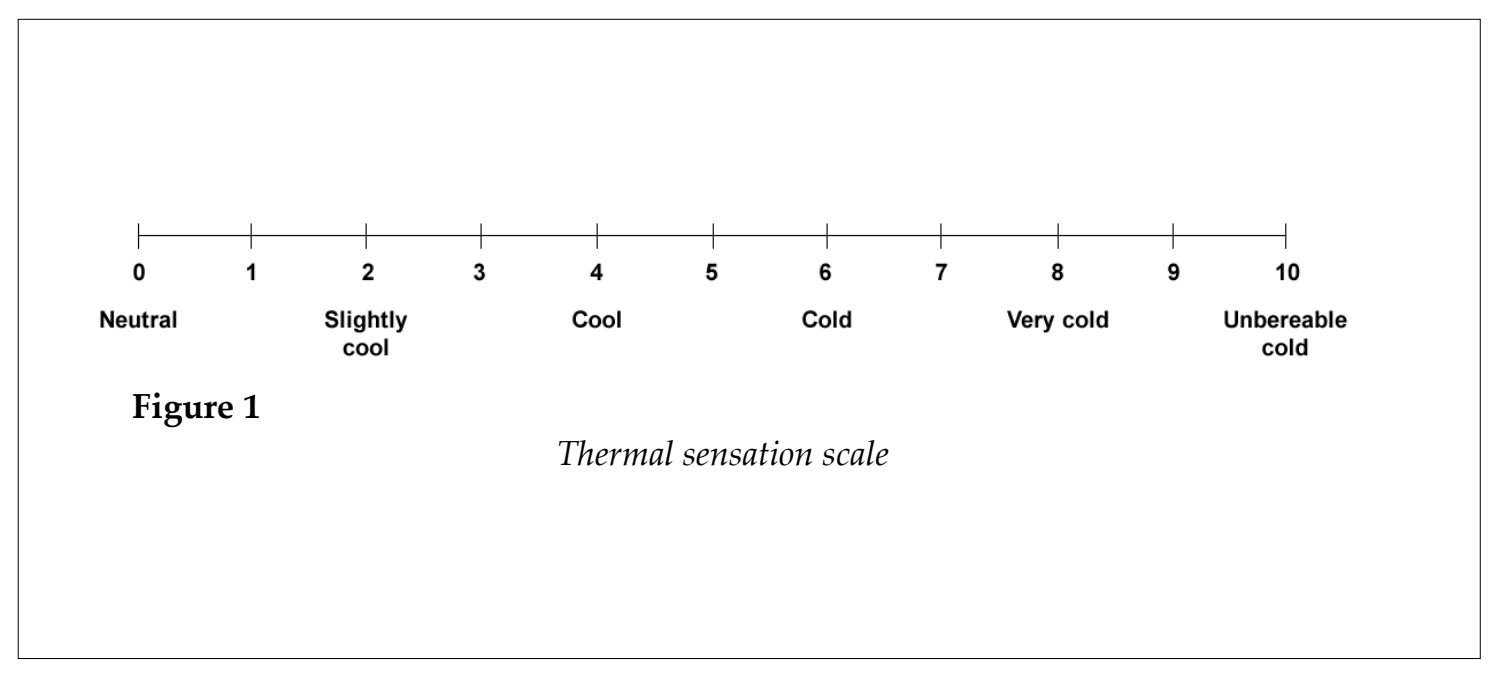




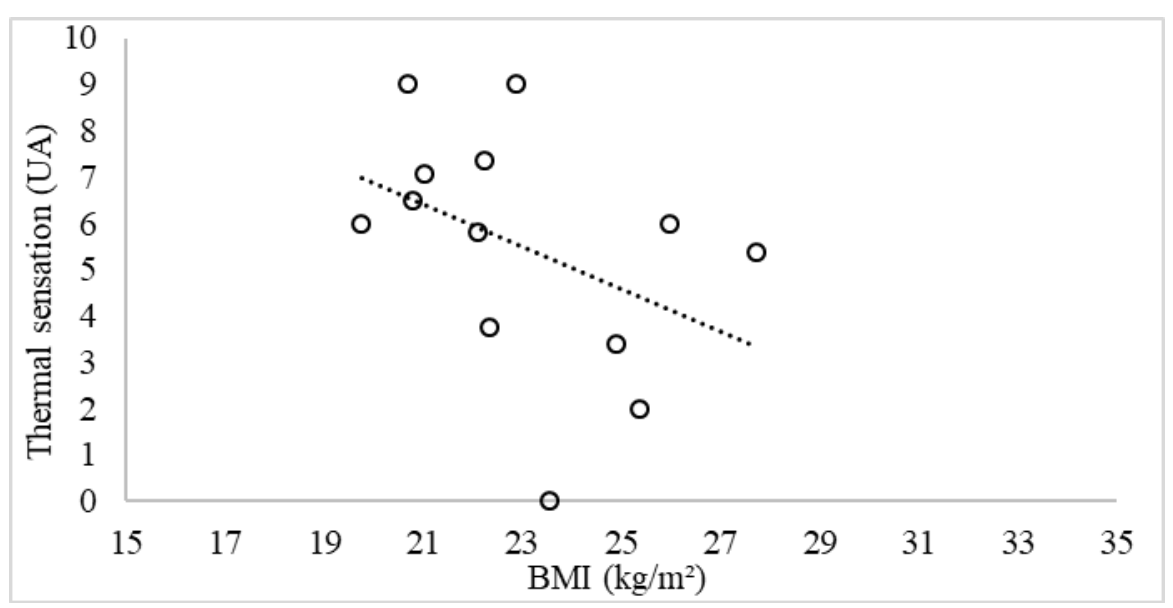

Figure 2

Results of the Spearman correlation test between thermal sensations after 3 min of exposure and the BMI in female athletes

Table 1

Characteristics of the 24 athletes (expressed as the mean \pm standard deviation)

\begin{tabular}{cccc} 
& All & Males & Females \\
\hline Age (years) & $25.7 \pm 3.5$ & $25.5 \pm 3.6$ & $25.9 \pm 3.5$ \\
Body mass $(\mathrm{kg})$ & $88.5 \pm 15.7$ & $100.2 \pm 12.4$ & $78.5 \pm 10.7$ \\
Body Height $(\mathrm{cm})$ & $192.5 \pm 11.8$ & $201.9 \pm 7.2$ & $184.5 \pm 8.6$ \\
BMI $\left(\mathrm{kg} / \mathrm{m}^{2}\right)$ & $23.7 \pm 2.3$ & $24.5 \pm 2.0$ & $23.0 \pm 2.4$ \\
BSA $\left(\mathrm{m}^{2}\right)$ & $2.18 \pm 0.25$ & $2.39 \pm 0.18$ & $2.01 \pm 0.17$ \\
& & & \\
BSA $/ \mathrm{BM}\left(\mathrm{cm}^{2} / \mathrm{kg}\right)$ & $2.50 \pm 0.17$ & $2.39 \pm 0.13$ & $2.58 \pm 0.16$
\end{tabular}


Table 2

Perception of thermal sensation (Mean $\pm S D$ ) and extreme observed values in brackets during a 3-min whole-body cryostimulation exposure in 24 athletes

\begin{tabular}{cccccc}
$30 \mathrm{~s}$ & $60 \mathrm{~s}$ & $90 \mathrm{~s}$ & $120 \mathrm{~s}$ & $150 \mathrm{~s}$ & $180 \mathrm{~s}$ \\
\hline $3.0 \pm 1.7^{*}$ & $3.8 \pm 1.7 \S$ & $4.3 \pm 1.7^{\ddagger 1 ।}$ & $4.7 \pm 1.98 \mathrm{sI}$ & $5.3 \pm 2.1^{11 * *}$ & $5.7 \pm 2.3^{\mathrm{II}}$
\end{tabular}

All athletes

$\begin{array}{lccccc}(0.0-7.0) & (0.0-7.5) & (0.0-8.0) & (0.0-9.0) & (0.0-9.5) & (0.0-10.0) \\ 2.9 \pm 1.6^{\ddagger} & 3.8 \pm 1.4^{+\S ॥ \mid ⿻} & 4.5 \pm 1.5 & 4.9 \pm 1.6 & 5.5 \pm 1.9 & 6.0 \pm 1.9\end{array}$

Males

\begin{tabular}{|c|c|c|c|c|c|}
\hline$(1.0-6.0)$ & $(2.0-6.0)$ & $(2.0-8.0)$ & $(3.0-9.0)$ & $(3.0-9.5)$ & $(3.0-10.0)$ \\
\hline $3.1 \pm 1.8^{\ddagger}$ & $3.8 \pm 2.0+\S 11$ & $4.2 \pm 1.9 \neq \| \mathbb{\|}$ & $4.6 \pm 2.1+\$ \llbracket * *$ & $5.2 \pm 2.4 \S ॥ * *$ & $5.5 \pm 2.6^{\|} \mid \mathbb{\|}$ \\
\hline
\end{tabular}

Females
$(0.0-7.0)$
$(0.0-7.5)$
$(0.0-8.0)$
$(0.0-8.0)$
$(0.0-9.0)$
$(0.0-9.0)$

(Abbreviations: * significantly different from the data obtained at other time points;

Value significantly different from the data obtained at other time points: except for $30 \mathrm{s:}$;; Except for $60 \mathrm{s:}$ :; Except for $90 \mathrm{~s}$ : s; Except for $120 \mathrm{~s}$ : ${ }^{\prime}$; Except for $150 \mathrm{s:}$ I; Except for $180 \mathrm{s:}{ }^{* *}$ )

\section{Discussion}

This study was undertaken to evaluate the thermal sensation during PBC exposure in international-level athletes in situ during periods of competition. Relevant and valuable outcomes concerning thermal perception during $\mathrm{PBC}$ exposure were obtained.

The main finding of this study is that PBC does not seem to represent a high thermal perceptual strain for the majority of the participating athletes. However, we observed a large inter-individual variation in the perceived thermal sensations. The female athletes with the lowest BMI had the highest scores in the thermal scale we used.

Thermal sensation scores gradually increased during the course of the 3-min exposure, with the scores rapidly increasing during the first minute and then stabilizing during the final two minutes. After the total exposure time $(3 \mathrm{~min})$, the mean perceived thermal sensation score was 5.7, which indicates a "cool" sensation. Therefore, a 3-min exposure at $130{ }^{\circ} \mathrm{C}$ did not appear to add unnecessary strain 
for the majority of the athletes during the competition phase. The maximum score of perceived thermal sensation (coldest sensation $=$ 10) was reached only at $180 \mathrm{~s}$ in one subject. The majority of the participants did not feel especially cold after the end of the exposure. Nevertheless, at $30 \mathrm{~s}$, three participants reported relatively high perceived thermal sensation scores $(\geq 6)$, and their cold-induced discomfort worsened as the exposure continued.

The second important finding of this study is the negative correlation between the BMI of the athletes and thermal sensations, especially in females, during the exposure. It seems that the morphology of the participants may influence heat transfer from the body to the environment, especially as the duration of cold exposure increases. Recently, Cholewka et al. (2012) demonstrated that the magnitude of the skin temperature response to extremely low temperatures used in WBC was dependent on individual features, such as the BMI. Depending on age and sex, the BMI has been shown to be closely correlated with body fat (Gallagher et al., 1996), and it is known that fat tissues in skin or in muscles may act as thermal insulation. Therefore, the subjects with a lower BMI may be more prone to transfer heat and may be more sensitive to the cold environment. The gender-linked discrepancy in thermal sensation could be related to different thermoregulation abilities in males and females. This might be explained by anthropometric and thermoregulatory differences. Indeed, females have $20 \%$ lower body mass, $14 \%$ more fat, $33 \%$ less lean body mass and $18 \%$ less surface area (Burse, 1979) and a higher subcutaneous to visceral fat ratio than males (Enzi et al., 1986). Moreover, when exposed to cold environments, females generally have a lower ability to shiver (Burse, 1979) and a greater reduction in skin temperature than males (Cuttell et al., 2017; Hammond et al., 2014; Stocks et al., 2004). This may explain, in part, the higher scores for cold sensation recorded by females.

It has also been shown that the temperature in an empty cryocabin is lower than in a cryocabin with a participant inside (Savic et al., 2013). Therefore, the morphology of the participant and the duration of the exposure could influence the temperature inside the cryocabin. Currently, chamber temperature cannot be monitored continuously, and the actual cold stimulation may not have been completely consistent among participants. The only temperature control is performed at the position of the nitrogen nozzle. Recent investigation showed that temperature variation may occur next to the skin $\left(5-10{ }^{\circ} \mathrm{C}\right.$ depending on the subjects) (Savic et al., 2013). Moreover, significant temperature differences were shown among different body regions due to the colder temperature at the bottom of the cabin (cold air has higher density than warm air). Furthermore, PBC consists of an open tank at the head level that facilitates the entry of warmer air into the system; the system does not provide a constant and homogeneous temperature in the cabin. In our setting, subjects with the lowest BMI might be more sensitive to cold exposure (higher cold perception), have transferred a higher amount of heat during the exposure or have been subjected to colder temperatures than subjects with a higher BMI.

Globally, a 3-min exposure at $-130{ }^{\circ} \mathrm{C}$ is well tolerated by athletes and can be used during a heavy competition period and/or during a training period when the load of physical exercise is very important. $\mathrm{PBC}$ is not perceived as extremely uncomfortable or stressful by most athletes; however, special attention should be given to female athletes with a low BMI as they seem to be much more sensitive to cold. Our recently published review emphasizes that further studies should be developed to analyse thermal sensation in connection to the physical characteristics and gender of the participants to be able to provide the most relevant PBC exposure (Bouzigon et al., 2016). The link found between the BMI and cold-perceived sensation should be explored with further analysis including subcutaneous (and even intramuscular) fat content. Technical improvements concerning temperature monitoring during cold exposure are also necessary so that the chamber can be adjusted to a given temperature throughout the exposure and to allow for an even temperature in the chamber. Indeed, only two studies have presented the actual temperature in a PBC device (Criomed, Kherson, Ukraine) and a WBC device (Cryantal Developpement, Noisiel, France) during an exposure (Bouzigon et al., 2017; Savic et al., 2013). 


\section{Acknowledgements}

We thank all the volunteers and their professional teams who participated in this study. Samuel Queniart and Jean Gratacos and their team from Cryantal are also warmly thanked for their logistic support. The experiment performed in this study complies with the current laws of the French country.

\section{References}

Banfi C, Melegati G, Barassi A, Dogliotti G, Melzi d'Eril G, Dugue B. Corsi M. Effects of whole-body cryotherapy on serum mediators of inflammation and serum muscle enzymes in athletes. Journal of Thermal Biology, 2009; 34: 55-59

Banfi G, Lombardi G, Colombini A, Melegati G. Whole-body cryotherapy in athletes. Sports Medicine, 2010; 40(6): 509-517. doi:10.2165/11531940-000000000-00000

Bleakley CM, Hopkins JT. Is it possible to achieve optimal levels of tissue cooling in cryotherapy? Physical Therapy Reviews, 2010; 15(4): 344-350. doi:10.1179/174328810x12786297204873

Bouzigon R, Arfaoui A, Grappe F, Ravier G, Jarlot B, Dugue B. Validation of a new whole-body cryotherapy chamber based on forced convection. Journal of Thermal Biology, 2017; 65: 138-144. doi:http://dx.doi.org/10.1016/j.jtherbio.2017.02.019

Bouzigon R, Grappe F, Ravier G, Dugue B. Whole- and partial-body cryostimulation/cryotherapy: Current technologies and practical applications. Journal of Thermal Biology, 2016; 61: 67-81. doi:http://dx.doi.org/10.1016/j.jtherbio.2016.08.009

Bouzigon R, Ravier G, Dugue B, Grappe F. The use of whole-body cryostimulation to improve the quality of sleep in athletes during high level standard competitions. British Journal of Sports Medicine, 2014; 48(7): 572. doi:10.1136/bjsports-2014-093494.33

Burse RL. Sex differences in human thermoregulatory response to heat and cold stress. Human Factors, 1979; 21(6): 687-699

Cholewka A, Stanek A, Sieron A, Drzazga Z. Thermography study of skin response due to whole-body cryotherapy. Skin Research and Technology, 2012; 18(2): 180-187. doi:10.1111/j.1600-0846.2011.00550.x

Costello JT, Culligan K, Selfe J, Donnelly AE. Muscle, Skin and Core Temperature after $-110^{\circ} \mathrm{C}$ Cold Air and $8^{\circ} \mathrm{C}$ Water Treatment. PLoS One, 2012; 7(11). e48190. doi:10.1371/journal.pone.0048190

Cuttell S, Hammond L, Langdon D, Costello JT. Individualising the exposure of -110 degrees C whole body cryotherapy: The effects of sex and body composition. Journal of Thermal Biology, 2017; 65: 41-47. doi:10.1016/j.jtherbio.2017.01.014

Dugue B, Leppanen E. Adaptation related to cytokines in man: effects of regular swimming in ice-cold water. Clinical Physiology, 2000; 20(2): 114-121

Dugue BM. An attempt to improve Ferreira-Junior model concerning the anti-inflammatory action of wholebody cryotherapy after exercise induced muscular damage (EIMD). Frontiers in Physiology, 2015; 6: 35. doi:10.3389/fphys.2015.00035

Enzi G, Gasparo M, Biondetti PR, Fiore D, Semisa M, Zurlo F. Subcutaneous and visceral fat distribution according to sex, age, and overweight, evaluated by computed tomography. American Journal of Clinical Nutrition, 1986; 44(6): 739-746

Filaire E, Sagnol M, Ferrand C, Maso F, Lac G. Psychophysiological stress in judo athletes during competitions. Journal of Sports Medicine and Physical Fitness, 2001; 41(2): 263-268

Gallagher D, Visser M, Sepúlveda D, Pierson RN, Harris T, Heymsfield SB. How Useful Is Body Mass Index for Comparison of Body Fatness across Age, Sex, and Ethnic Groups? American Journal of Epidemiology, 1996; 143(3): 228-239

Glickman-Weiss EL, Nelson AG, Hearon CM, Goss FL, Robertson RJ, Cassinelli DA. Effects of body 
morphology and mass on thermal responses to cold water: revisited. European Journal of Applied Physiology and Occupational Physiology, 1993; 66(4): 299-303

Hammond LE, Cuttell S, Nunley P, Meyler J. Anthropometric Characteristics and Sex Influence Magnitude of Skin Cooling following Exposure to Whole Body Cryotherapy. BioMed Research International, 2014; 7

Harung HS, Travis F, Pensgaard AM, Boes R, Cook-Greuter S, Daley K. Higher psycho-physiological refinement in world-class Norwegian athletes: brain measures of performance capacity. Scandinavian Journal of Medicine E Science in Sports, 2011; 21(1): 32-41. doi:10.1111/j.1600-0838.2009.01007.x

Hausswirth C, Louis J, Bieuzen F, Pournot H, Fournier J, Filliard JR, Brisswalter J. Effects of whole-body cryotherapy vs. far-infrared vs. passive modalities on recovery from exercise-induced muscle damage in highly-trained runners. PLoS One, 2011; 6(12). e27749. doi:10.1371/journal.pone.0027749

Hohenauer E, Taeymans J, Baeyens JP, Clarys P, Clijsen R. The Effect of Post-Exercise Cryotherapy on Recovery Characteristics: A Systematic Review and Meta-Analysis. PLoS One, 2015; 10(9). e0139028. doi:10.1371/journal.pone.0139028

Hopkins WG, Marshall SW, Batterham AM, Hanin J. Progressive statistics for studies in sports medicine and exercise science. Medicine and Science in Sports and Exercise, 2009; 41(1): 3-13. doi:10.1249/MSS.0b013e31818cb278

Klimek AT, Lubkowska A, Szygula Z, Chudecka M, Fraczek B. Influence of the ten sessions of the whole body cryostimulation on aerobic and anaerobic capacity. International Journal of Occupational Medicine and Environmental Health, 2010; 23(2): 181-189. doi:10.2478/v10001-010-0019-2

Leppaluoto J, Westerlund T, Huttunen P, Oksa J, Smolander J, Dugue B, Mikkelsson M. Effects of long-term whole-body cold exposures on plasma concentrations of ACTH, beta-endorphin, cortisol, catecholamines and cytokines in healthy females. Scandinavian Journal of Clinical and Laboratory Investigation, 2008; 68(2): 145-153. doi:10.1080/00365510701516350

Lombardi G, Ziemann E, Banfi G. Whole-body cryotherapy in athletes from therapy to stimulation. An updated review of the literature. Frontiers in Physiology, 2017; 8. doi: 10.3389/fphys.2017.00258

Lundgren P, Henriksson O, Kuklane K, Holmer I, Naredi P, Bjornstig U. Validity and reliability of the Cold Discomfort Scale: a subjective judgement scale for the assessment of patient thermal state in a cold environment. Journal of Clinical Monitoring and Computing, 2014; 28(3): 287-291. doi:10.1007/s10877-0139533-7

Mila-Kierzenkowska C, Jurecka A, Wozniak A, Szpinda M, Augustynska B, Wozniak B. The effect of submaximal exercise preceded by single whole-body cryotherapy on the markers of oxidative stress and inflammation in blood of volleyball players. Oxidative Medicine and Cellular Longevity, 2013; 10. doi:10.1155/2013/409567

Miller E, Kostka J, Wlodarczyk T, Dugue B. Whole-body cryostimulation (cryotherapy) provides benefits for fatigue and functional status in multiple sclerosis patients. A case-control study. Acta Neurologica Scandinavica. 2016. doi:10.1111/ane.12557

Mikołajec K, Maszczyk A, Chalimoniuk M, Langfort J, Gołaś A, Zajc A. The influence of strength exercises of the lower limbs on postural stability: A possible role of the autonomic nervous system. Isokinet Exerc Sci. 2017; 25(2): 79-89

Pournot H, Bieuzen F, Louis J, Mounier R, Fillard JR, Barbiche E, Hausswirth C. Time-course of changes in inflammatory response after whole-body cryotherapy multi exposures following severe exercise. PLoS One, 2011; 6(7). e22748. doi:10.1371/journal.pone.0022748

Savic M, Fonda B, Sarabon N. Actual temperature during and thermal response after whole-body cryotherapy in cryo-cabin. Journal of Thermal Biology, 2013; 38(4): 186-191. doi:http://dx.doi.org/10.1016/j.jtherbio.2013.02.004 
Sternberg WF, Bailin D, Grant M, Gracely RH. Competition alters the perception of noxious stimuli in male and female athletes. Pain, 1998; 76(1-2): 231-238

Stocks JM, Taylor NA, Tipton MJ, Greenleaf JE. Human physiological responses to cold exposure. Aviation, Space, and Environmental Medicine, 2004; 75(5): 444-457

Sutkowy P, Augustynska B, Wozniak A, Rakowski A. (Physical exercise combined with whole-body cryotherapy in evaluating the level of lipid peroxidation products and other oxidant stress indicators in kayakers. Oxidative Medicine and Cellular Longevity, 2014; 7. doi:10.1155/2014/402631

Zhang H, Huizenga C, Arens E, Yu T. Considering individual physiological differences in a human thermal model. Journal of Thermal Biology, 2001; 26(4-5): 401-408. doi:http://dx.doi.org/10.1016/S03064565(01)00051-1

\section{Corresponding author:}

\section{Romain Bouzigon,}

Université de Franche Comté, Laboratoire C3S (EA 4660), Unité de Promotion, de Formation et de Recherche (UPFR) des Sports, 31 rue de l'Epitaphe, 25000 Besançon, France.

Société Cryantal Développement, 15 cours du Luzard, 77186 Noisiel, France.

Author personal address: 16 rue des Geais, 39270 PLAISIA, France.

Phone number: (+33)6.70.27.93.27

E-mail: romain.bouzigon@gmail.com 